\title{
Risk of perinatal mortality associated with asthma during pregnancy
}

\author{
M-C Breton, ${ }^{1}$ M-F Beauchesne, ${ }^{1,2}$ C Lemière, ${ }^{2}$ É Rey, ${ }^{3}$ A Forget, ${ }^{2}$ L Blais ${ }^{2}$
}

\section{See Editorial, p 93}

${ }^{1}$ Faculty of Pharmacy, Université de Montréal, Montréal, Québec, Canada; ${ }^{2}$ Research Center, Hôpital du Sacré-Cœur de Montréal, Montréal, Québec, Canada; ${ }^{3}$ Obstetric and Gynecology Department, Obstetric and Gynecology Department, CHU Ste-Justine, Montréal, Québec, Canada

Correspondence to: Dr L Blais, Université de Montréal, Faculté de Pharmacie,

C.P. 6128, succursale Centreville, Montréal (Québec) Canada, H3C 3J7; lucie.blais@ umontreal.ca

Received 10 June 2008 Accepted 15 October 2008 Published Online First 13 November 2008

\begin{abstract}
Background: Thirteen studies investigating the association between asthma during pregnancy and perinatal mortality reported generally no increased risk. Most of these studies should be interpreted with caution because they were limited in terms of statistical power. A study was therefore undertaken to evaluate whether maternal asthma during pregnancy increases the risk of perinatal mortality.

Methods: Through three administrative databases from Québec (Canada), a cohort of women with and without asthma who had at least one pregnancy between 1990 and 2002 was formed. Perinatal mortality was identified by diagnostic codes. The adjusted odds ratio (OR) of perinatal mortality in women with and without asthma was compared using Generalised Estimation Equation (GEE) models. The first model included all potential confounders (except small for gestational age, SGA), the second model excluded birth weight, gestational age at birth and SGA and the third model excluded birth weight, gestational age at birth but included only SGA. This analysis was also stratified for birth weight and gestational age at birth.
\end{abstract}

Results: The cohort was formed of 13100 and 28042 single pregnancies in women with and without asthma. The crude OR of perinatal mortality was 1.35 (95\% Cl 1.08 to 1.67$)$, which decreased to $0.93(95 \% \mathrm{Cl} 0.75$ to 1.17$)$ after adjustment for birth weight and gestational age at birth. Women with asthma had a higher rate of low birthweight babies and preterm delivery than those without asthma.

Conclusion: The increased risk of low birthweight babies and premature delivery in women with asthma may partly explain the association between maternal asthma and the increased risk of perinatal mortality.

Asthma is considered the most prevalent medical condition to complicate pregnancy. ${ }^{1}$ Around 4-8\% of pregnancies are complicated by asthma. ${ }^{1}$ Most studies that have evaluated the effect of maternal asthma on perinatal mortality suggest that it does not significantly increase the risk, ${ }^{2-12}$ but Gordon et $a l^{13}$ reported a statistically significant increased risk of perinatal mortality among 273 women with asthma compared with 30861 non-asthmatic women $(5.9 \%$ vs $3.2 \%$, p $<0.05)$. It is worth noting, however, that the conclusion of this study was based on crude estimates. The risk of stillbirth ${ }^{2}$ 14-21 and neonatal mortality ${ }^{814-1720}$ associated with maternal asthma has been evaluated in several studies but no statistically significant increased risk was reported, except in the study by Bahna et al. ${ }^{2}$ Moreover, most of the negative studies should be interpreted with caution owing to small sample size and lack of power ${ }^{3-11}$ that limits the capacity of the studies to conclude the absence of an association with a reasonable degree of certainty. Among the negative studies, Tata et $a^{21}$ were the only authors who performed a study with a power of $>80 \%$ to detect the observed relative risk.

In order to better quantify the association between maternal asthma and perinatal mortality, we conducted a large cohort study of 41142 pregnancies in women with and without asthma using the health administrative databases of the Canadian province of Québec.

\section{METHODS}

\section{Source of data}

Our cohort of pregnancies was constructed through the linkage of three health administrative databases from Québec, Canada. The administrative database of the Régie de l'assurance-maladie du Québec (RAMQ) provides information related to the medical services dispensed to all residents of Québec as well as information related to medication prescriptions filled at community pharmacies for those residents who are covered by the Quebec's Public Prescription Drug Insurance Plan, which represents approximately $43 \%$ of the population. The MED-ECHO database contains information on all hospital admissions in Québec. Administered by the Institut de la statistique du Québec (ISQ), the Fichier des événements démographiques provides information on all births and perinatal deaths.

\section{Study population}

We constructed a cohort formed of singleton pregnancies of all women with asthma and a $33 \%$ random sample of women without asthma who had at least one delivery (live birth or stillbirth) between 1990 and 2002, were covered by the Quebec's Public Prescription Drug Insurance Plan for at least 1 year before conception and during pregnancy, and were aged $13-50$ years at conception. Pregnancies were identified using diagnostic and act codes related to prenatal care, pregnancy complications and delivery care. The calendar date of the conception, the first day of the last menstrual period, was retrospectively calculated by subtracting the gestational age from the offspring's date of birth as recorded in the MEDECHO and RAMO databases. These databases have been used in the past for epidemiological research in the field of asthma. ${ }^{22}$

The main exposure was maternal asthma. A woman was considered to have asthma if she had filled at least one prescription for an asthma medication and had at least one diagnosis of asthma in accordance with the International 
Classification of Diseases, 9th revision (ICD-9) codes 493.0, 493.1, 493.9, 2 years before or during her pregnancy. Once a woman was identified as having asthma, her status was kept unchanged for all subsequent pregnancies. The medical diagnosis for asthma recorded in the RAMO Medical Services database has been formally evaluated and found to be valid. ${ }^{23} \mathrm{~A}$ women was considered to be non-asthmatic if she filled no prescription for an asthma medication between 1988 and 2002 and had no diagnosis for asthma during the entire follow-up period.

\section{Definition of outcomes}

Perinatal mortality included stillbirth and neonatal mortality. Stillbirth was defined as fetal loss beyond 20 weeks of gestation or, if the gestational age is unknown, a birth weight of $\geqslant 500 \mathrm{~g}$ which corresponds to 22 weeks of gestation in a normally developing fetus. Stillbirths were identified with ICD-9 codes 656.4, V27.1, V27.3, V27.4, V27.6, V27.7, V32, V35, V36 recorded in the RAMO, MED-ECHO or birth and death certificate databases. Neonatal mortality was defined as the death of a liveborn neonate within the first 29 days of life. Deaths occurring within the first 29 days of life were identified from the ISO or RAMQ databases.

\section{Potential confounding variables}

Three categories of variables identified in the literatureincluding maternal characteristics, pregnancy-related variables and fetal characteristics-were considered as potential confounders. Maternal characteristics included the age at conception ( $<18$ years, $18-34$ years, $\geqslant 35$ years), receiving benefits from Quebec's Social Assistance Program during the pregnancy (yes/no) and the level of education during the pregnancy ( $\leqslant 11$ years $\geqslant 12$ years, missing values). The pregnancy-related variables included parity (first/second or more pregnancy), pregnancy induced hypertension (PIH) (yes/no), diabetes mellitus (yes/no), gestational diabetes (yes/no), placental abruption (yes/no) and infection of amniotic cavity (yes/no). Using specific algorithms that we developed for each condition, $\mathrm{PIH}$, gestational diabetes and diabetes mellitus were identified based upon either a diagnosis or a filled prescription for a related medication as recorded in the RAMO or MED-ECHO databases 1 year before or during the pregnancy. These variables have been defined previously ${ }^{24}$ and the algorithms are available on request. Fetal characteristics included cord around the neck (yes/no) based on a diagnosis recorded in the RAMQ or MEDECHO databases, as well as birth weight ( $\leqslant 2500 \mathrm{~g} />2500 \mathrm{~g})$, gestational age at birth ( $<37$ weeks $>37$ weeks) and small for gestational age (SGA) (yes/no). Algorithms to measure birth weight and gestational age at birth from the data available in the MED-ECHO and ISQ databases have been developed and found to be highly valid when compared with data recorded in the mother's medical chart. ${ }^{25}$

\section{Statistical analysis}

To compare the risk of perinatal mortality between women with and without asthma, Generalised Estimation Equation (GEE) models with a logistic link were used and potential confounders were included in the models. GEE models were used to estimate the correlation between pregnancies from the same women and to provide valid variance estimates. Seven models were used: (1) a crude model including only the maternal asthma variable (main exposure); (2) a full and a reduced model including the maternal asthma variable and considering all potential confounding variables except SGA; (3) a full and a reduced model including the maternal asthma variable and considering all potential confounding variables except birth weight, gestational age at birth and SGA; (4) a full and a reduced model including the maternal asthma variable and considering all potential confounding variables except birth weight and gestational age.

Since maternal asthma has been found to increase the risk of having a low birthweight baby, ${ }^{25}{ }^{17}$ premature delivery ${ }^{217} 26$ and perinatal death, ${ }^{27}$ we performed a stratified analysis to further investigate the role of these variables in the causal pathway between maternal asthma and perinatal mortality. The association between maternal asthma and perinatal mortality was therefore separately studied in women who had a baby with a birth weight $\leqslant 2500$ g or born before the 37 th week of gestation and in women who had a baby with a birth weight $>2500 \mathrm{~g}$ and born at 37 weeks of gestation or more. These analyses were adjusted for all potential confounding variables listed above except SGA.

A backward selection strategy was used to select the set of confounders. This strategy consists of eliminating one by one the variables that do not act as confounders in the model, starting with all potential confounding variables in the model. When a variable was excluded from the model and the odds ratio of asthma changed by more than $10 \%$, we considered it to be a confounder and it was reintroduced into the model. The final model was obtained when no variable could be removed from the model without modifying the odds ratio of maternal asthma by $10 \%$ or more. Analyses were performed using SAS Version 9.

\section{RESULTS}

The cohort was formed of 41142 singleton pregnancies, 13100 in women with asthma and 28042 in women without asthma. The rates of stillbirth and perinatal mortality in women with asthma were $0.56 \%$ and $1.04 \%$, respectively, compared with $0.47 \%$ and $0.77 \%$ in women without asthma.

The characteristics of the pregnant women with and without asthma included in the cohort are shown in table 1 . The unit of analysis is the pregnancy, since $23 \%$ of the women contributed more than one pregnancy in the analysis. Women with asthma were more likely to have a low birthweight baby and a preterm delivery than those without asthma. Table 1 also shows the prevalence of perinatal mortality as a function of each covariable: women who had a placental abruption, an infection of the amniotic cavity, a low birthweight baby and a premature delivery had a greater risk of perinatal mortality.

The results of the GEE models that were used to investigate the risk of perinatal mortality between women with and without asthma, including all potential confounding variables except SGA, are shown in table 2. A statistically significant crude increased risk of perinatal mortality was observed among women with asthma compared with those without asthma (OR1.35 (95\% CI 1.08 to 1.67)). After adjusting for all potential confounders, the OR decreased to 0.93 (95\% CI 0.75 to 1.17). The reduced model revealed that only birth weight and gestational age at birth acted as confounders in the association between asthma and perinatal mortality. It is also worth noting that low birth weight and preterm birth were found to be very strong crude predictors of perinatal mortality with significant ORs of 34.8 and 30.6, but these ORs reduced to 9.11 and 7.07, respectively, after adjusting for maternal asthma. On the other hand, the full and the reduced models excluding birth weight, gestational age at birth and SGA showed that women with 
Table 1 Characteristics of pregnant women with and without asthma

\begin{tabular}{|c|c|c|c|c|}
\hline & \multicolumn{2}{|c|}{ Asthmatic women } & \multicolumn{2}{|c|}{ Non-asthmatic women } \\
\hline & $\begin{array}{l}\text { Pregnancies } \\
(n=13100)\end{array}$ & $\begin{array}{l}\text { Perinatal deaths } \\
(\mathrm{n}=136)\end{array}$ & $\begin{array}{l}\text { Pregnancies } \\
(\mathrm{n}=28042)\end{array}$ & $\begin{array}{l}\text { Perinatal deaths } \\
(\mathrm{n}=\mathbf{2 1 7 )}\end{array}$ \\
\hline & n (\%) & n (\%) & n (\%) & n (\%) \\
\hline \multicolumn{5}{|c|}{ Maternal characteristics } \\
\hline \multicolumn{5}{|c|}{ Age (years) } \\
\hline$<18$ & $881(6.7)$ & $9(1.0)$ & $994(3.6)$ & $9(0.9)$ \\
\hline $18-34$ & $11411(87.1)$ & $117(1.0)$ & $24353(86.8)$ & $173(0.7)$ \\
\hline$\geqslant 35$ & $808(6.2)$ & $10(1.2)$ & $2695(9.6)$ & $35(1.3)$ \\
\hline \multicolumn{5}{|c|}{ Social assistance } \\
\hline Yes & $10420(79.5)$ & $113(1.1)$ & $16091(57.4)$ & $136(0.9)$ \\
\hline No & $2680(20.5)$ & $23(0.9)$ & $11951(42.6)$ & $81(0.7)$ \\
\hline \multicolumn{5}{|c|}{ Level of education } \\
\hline$\leqslant 11$ & 7795 (59.5) & $66(0.9)$ & $11816(42.2)$ & $85(0.7)$ \\
\hline$\geqslant 12$ & $4336(33.1)$ & $23(0.6)$ & $13925(49.6)$ & $59(0.6)$ \\
\hline Missing & $969(7.4)$ & $47(4.9)$ & $2301(8.2)$ & $73(3.2)$ \\
\hline \multicolumn{5}{|c|}{ Pregnancy-related variables } \\
\hline \multicolumn{5}{|c|}{ Parity } \\
\hline 1 & $4190(32.0)$ & $34(0.8)$ & $9620(34.3)$ & $65(0.7)$ \\
\hline$\geqslant 2$ & $8843(67.5)$ & $86(1.0)$ & $18168(64.8)$ & $132(0.7)$ \\
\hline \multicolumn{5}{|l|}{$\mathrm{PIH}$} \\
\hline Yes & $845(6.4)$ & $13(1.5)$ & $1440(5.1)$ & $11(0.8)$ \\
\hline No & $12255(93.6)$ & $123(1.0)$ & $26602(94.9)$ & $206(0.8)$ \\
\hline \multicolumn{5}{|c|}{ Diabetes mellitus } \\
\hline Yes & $309(2.4)$ & $5(1.6)$ & $368(1.3)$ & $6(1.6)$ \\
\hline No & $12790(97.6)$ & $130(1.0)$ & $27670(98.7)$ & $207(0.8)$ \\
\hline \multicolumn{5}{|c|}{ Gestational diabetes } \\
\hline Yes & $1008(7.7)$ & $11(1.1)$ & $1899(6.8)$ & $9(0.5)$ \\
\hline No & $12091(92.3)$ & $124(1.0)$ & $26139(93.2)$ & $204(0.8)$ \\
\hline \multicolumn{5}{|c|}{ Placental abruption } \\
\hline Yes & $486(3.7)$ & $28(5.8)$ & $844(3.0)$ & $39(4.6)$ \\
\hline No & $12614(96.3)$ & $108(0.9)$ & $27198(97.0)$ & $178(0.7)$ \\
\hline \multicolumn{5}{|c|}{ Infection of amniotic cavity } \\
\hline Yes & $608(4.6)$ & $18(3.0)$ & $1407(5.0)$ & $38(2.7)$ \\
\hline No & $12492(95.4)$ & $118(0.9)$ & $26635(95.0)$ & $179(0.7)$ \\
\hline \multicolumn{5}{|c|}{ Fetal characteristics } \\
\hline \multicolumn{5}{|c|}{ Cord around neck } \\
\hline Yes & $2202(16.8)$ & $14(0.6)$ & $4990(17.8)$ & $34(0.7)$ \\
\hline No & $10898(83.2)$ & $122(1.1)$ & $23052(82.2)$ & $183(0.8)$ \\
\hline \multicolumn{5}{|l|}{ Birth weight } \\
\hline$\leqslant 2500 \mathrm{~g}$ & $1211(9.2)$ & $97(8.0)$ & $1599(5.7)$ & $150(9.4)$ \\
\hline$>2500 \mathrm{~g}$ & $11889(90.8)$ & $39(0.3)$ & $26443(94.3)$ & $67(0.3)$ \\
\hline \multicolumn{5}{|c|}{ Gestational age at birth } \\
\hline$<37$ weeks & $1359(10.4)$ & $104(7.7)$ & $1887(6.7)$ & $146(7.7)$ \\
\hline$\geqslant 37$ weeks & $11741(89.6)$ & $32(0.3)$ & $26155(93.3)$ & $71(0.3)$ \\
\hline \multicolumn{5}{|l|}{ SGA } \\
\hline Yes & $1888(14.4)$ & $27(1.4)$ & $2954(10.5)$ & $52(1.8)$ \\
\hline No & $11140(85.0)$ & $102(0.9)$ & $24876(88.7)$ & $155(0.6)$ \\
\hline
\end{tabular}

$\mathrm{PIH}$, pregnancy-induced hypertension; SGA, small for gestational age.

asthma tended to be more at risk of perinatal mortality than women without asthma (adjusted OR 1.25 (95\% CI 0.98 to 1.58 ) in the full model and adjusted OR 1.30 (95\% CI 1.05 to $1.57)$ in the reduced model). The reduced model showed that only placental abruption (OR 7.24) acted as a confounder. Similar results were found in the full and reduced models including SGA as a potential confounder while excluding birth weight and gestational age at birth (OR for maternal asthma 1.17 (95\% CI 0.91 to 1.59 ) in the full model and 1.22 (95\% CI 0.98 to 1.53 ) in the reduced model). Only SGA (OR 2.21) and placental abruption (OR 7.41) were found to act as confounders in this reduced model.

The results of the stratified analysis are shown in table 3 . In the first stratum formed of normal weight $(>2500 \mathrm{~g})$ and term babies ( $\geqslant 37$ weeks) there were 11283 and 25552 pregnancies in women with and without asthma, respectively. In this stratum, after adjustment for all potential confounders, women with asthma were not found to be at increased risk of perinatal mortality (OR 0.97 (95\% CI 0.74 to 1.29)) compared with women without asthma. In the second stratum formed of 
Table 2 Crude and adjusted odds ratios (ORs) of perinatal mortality in women with and without asthma for the complete and final model $(n=41$ 142)

\begin{tabular}{|c|c|c|c|}
\hline & Crude OR $(95 \% \mathrm{Cl})$ & $\begin{array}{l}\text { Adjusted OR for all } \\
\text { covariates ( } 95 \% \text { CI) }\end{array}$ & $\begin{array}{l}\text { Adjusted OR for } \\
\text { confounders only (95\% } \\
\text { CI) }\end{array}$ \\
\hline Asthma yes/no & 1.35 (1.08 to 1.67$)$ & 0.95 (0.74 to 1.22$)$ & $0.93(0.75$ to 1.17$)$ \\
\hline \multicolumn{4}{|l|}{ Age } \\
\hline$<18$ & $1.19(0.73$ to 1.91$)$ & 0.91 (0.49 to 1.69$)$ & $\dagger$ \\
\hline $18-34$ & Reference (-) & Reference (-) & \\
\hline$\geqslant 35$ & $1.59(1.16$ to 2.18$)$ & $1.40(0.97$ to 2.01$)$ & \\
\hline Social assistance yes/no & $1.32(1.05$ to 1.67$)$ & $0.80(0.60$ to 1.06$)$ & $\dagger$ \\
\hline \multicolumn{4}{|l|}{ Level of education } \\
\hline$\leqslant 11$ & $1.25(0.98$ to 1.59$)$ & $0.95(0.72$ to 1.26$)$ & $\dagger$ \\
\hline$\geqslant 12$ & Reference (-) & Reference (-) & - \\
\hline Missing & 4.49 (3.39 to 5.95$)$ & $2.44(1.73$ to 3.45$)$ & \\
\hline \multicolumn{4}{|l|}{ Parity } \\
\hline 1 & Reference (-) & $1.12(0.86$ to 1.47$)$ & $\dagger$ \\
\hline$\geqslant 2$ & $1.13(0.89$ to 1.43$)$ & Reference & \\
\hline PIH yes/no & $1.24(0.82$ to 1.89$)$ & $0.53(0.32$ to 0.87$)$ & $\dagger$ \\
\hline Diabetes mellitus yes/no & $1.97(1.07$ to 3.60$)$ & $1.58(0.79$ to 3.18$)$ & $\dagger$ \\
\hline Gestational diabetes yes/no & $0.80(0.51$ to 1.26$)$ & $0.72(0.43$ to 1.21$)$ & $\dagger$ \\
\hline Placental abruption yes/no & 7.33 (5.59 to 9.62 ) & 1.75 (1.28 to 2.40$)$ & $\dagger$ \\
\hline Infection of amniotic cavity yes/no & $3.74(2.80$ to 4.99$)$ & $1.92(1.37$ to 2.68$)$ & $\dagger$ \\
\hline Cord around neck yes/no & $0.74(0.55$ to 1.01$)$ & $0.86(0.61$ to 1.21$)$ & $\dagger$ \\
\hline Birth weight $\leqslant 2500 />2500 \mathrm{~g}$ & 34.75 (27.58 to 43.79$)$ & $10.55(7.40$ to 15.15$)$ & $9.11(6.61$ to 15.55$)$ \\
\hline $\begin{array}{l}\text { Gestational age at birth }<37 / \geqslant 37 \\
\text { weeks }\end{array}$ & 30.62 (24.27 to 38.63$)$ & 6.24 (4.37 to 8.90$)$ & 7.07 (5.12 to 9.77$)$ \\
\hline
\end{tabular}

$\mathrm{PIH}$, pregnancy-induced hypertension.

$\dagger$ Not a confounder variable.

babies with a birth weight $<2500 \mathrm{~g}$ or born before the 37 th week of gestation, there were 1817 and 2490 pregnancies in women with and without asthma, respectively. In this stratum, asthma was also not found to be associated with an increased risk of perinatal mortality (OR 0.94 (95\% CI 0.73 to 1.22)).

\section{DISCUSSION}

In this study we observed a crude significant increased risk of perinatal mortality of $35 \%$ among women with asthma compared with women without asthma that did not remain after adjustment for birth weight and gestational age at birth. However, models excluding these variables or adjusted for SGA reveled that women with asthma tended to be more at risk of perinatal mortality than those without asthma. A stratified analysis showed that, among normal weight and term babies, maternal asthma during pregnancy did not increase the risk of perinatal death. Moreover, the proportions of low birthweight and preterm babies were higher in women with asthma than in those without asthma, and birth weight and gestational age at birth were very strong predictors of perinatal mortality. These results suggest that birth weight and gestational age at birth are likely to be in the causal pathway between asthma and perinatal mortality.

Twenty previously published studies investigated the association between maternal asthma and stillbirth, neonatal mortality and/or perinatal mortality. ${ }^{2-21}$ A significant increased risk of neonatal mortality and perinatal mortality in women with asthma was reported in only two studies, ${ }^{2}{ }^{13}$ but 10 of the studies $^{2} 691012-1619$ reported only crude estimates. Gordon et al ${ }^{13}$ were the only authors to report a statistically significant increased risk of perinatal mortality among 273 (5.9\%) women with asthma compared with 30861 (3.2\%) non-asthmatic women $(p<0.05)$, and only Bahna et al ${ }^{2}$ observed a significantly higher rate of neonatal mortality among 381women with asthma compared with 112530 women with no recorded disease before and during pregnancy $(p<0.05)$. These studies were performed in 1970 and 1972 at a time when neonatal intensive care was probably less sophisticated and fetal surveillance less intensive, explaining the high observed rate of perinatal mortality. Nevertheless, the crude relative risk estimate of perinatal mortality (1.84) is comparable to the crude OR of perinatal mortality (1.35) found in our study, both of them being statistically significant.

Table 3 Crude rate of perinatal mortality, crude and adjusted odds ratio (OR) of perinatal mortality in women with and without asthma in strata defined by birth weight and gestational age at birth

\begin{tabular}{|c|c|c|c|c|c|c|}
\hline & \multicolumn{2}{|c|}{ Asthmatic women } & \multicolumn{2}{|c|}{ Non-asthmatic women } & \multirow[b]{2}{*}{ Crude OR $(95 \% \mathrm{Cl})$} & \multirow[b]{2}{*}{ Adjusted OR $(95 \% \mathrm{CI})$} \\
\hline & $\begin{array}{l}\text { No of } \\
\text { pregnancies }\end{array}$ & $\begin{array}{l}\text { No }(\%) \text { of } \\
\text { perinatal deaths }\end{array}$ & $\begin{array}{l}\text { No of } \\
\text { pregnancies }\end{array}$ & $\begin{array}{l}\text { No }(\%) \text { of } \\
\text { perinatal deaths }\end{array}$ & & \\
\hline $\begin{array}{l}\text { Babies with a birth weight } \\
>2500 \mathrm{~g} \text { and gestational age at } \\
\text { birth } \geqslant 37 \text { weeks }\end{array}$ & 11283 & $27(0.2 \%)$ & 25552 & $51(0.2 \%)$ & $1.20(0.75$ to 1.91$)$ & $0.97(0.74$ to 1.29$)$ \\
\hline $\begin{array}{l}\text { Babies with a birth weight } \\
\leqslant 2500 \text { g or gestational age at } \\
\text { birth }<37 \text { weeks }\end{array}$ & 1817 & $109(6.0 \%)$ & 2490 & $166(6.7 \%)$ & $0.89(0.70$ to 1.15$)$ & $0.94(0.73$ to 1.21$)$ \\
\hline
\end{tabular}


Ten of these 20 studies $^{3-5} 781117182021$ reported estimates that were adjusted or matched for one or several confounding variables such as maternal age, body mass index (BMI) before pregnancy, parity, multiple pregnancy, smoking status, year of delivery, gestational diabetes, pre-existing diabetes, pre-existing hypertension, rupture of membrane and infection of amniotic cavity, and none of them found a significant increased risk of of stillbirth, neonatal mortality or perinatal mortality. The largest of these studies ${ }^{21}$ found that the risk of stillbirth was similar in 37585 pregnancies in women with asthma as in 243434 pregnancies in women without asthma after adjusting for maternal age, smoking status and BMI before pregnancy, year of birth, multiple pregnancy and sex of child (OR 1.04). None of these studies adjusted their results for birth weight or gestational age at birth.

Women with asthma during pregnancy have been found to be more at risk of having babies of low birth weight, ${ }^{2}{ }^{17}$ premature deliveries $^{21726}$ and placental abruption. ${ }^{26}$ Moreover, asthma exacerbations requiring hospitalisation during pregnancy, maternal asthma symptoms and poor asthma control have been associated with an increased risk of low birthweight babies, ${ }^{7}$ SGA babies ${ }^{15}$ and fetal growth restriction. ${ }^{29}$ In addition, these adverse perinatal and pregnancy outcomes have been found to increase the risk of perinatal mortality. ${ }^{27} 28$ Biological mechanisms could explain the relationship between maternal asthma and low birthweight and preterm babies. Fetal hypoxia (possibly due to poor asthma control) has been suggested as a mechanism for the association between asthma and intrauterine growth restriction. ${ }^{17} \mathrm{~A}$ hypoxic process at the maternal/fetal interface related to maternal asthma was also proposed to lead to placental abruption. ${ }^{31}$ Moreover, increased inflammatory cytokines and increased smooth muscle reactivity found in subjects with asthma may be associated with premature delivery. ${ }^{9}$ These data and those of Gordon et $a l^{13}$ on the association between severe asthma and perinatal mortality suggest that adequate control of asthma during pregnancy could reduce the risk of having low birthweight and preterm babies and, as a consequence, might reduce the risk of perinatal deaths in infants of women with asthma.

Our crude OR showed an increased risk of perinatal mortality among women with asthma, but our OR adjusted for birth weight and gestational age at birth and the ORs found in the stratified analysis showed no impact of maternal asthma during pregnancy on perinatal mortality. Indeed, in the stratified analysis we found no increased risk of perinatal mortality associated with asthma among normal weight and term babies and among low birthweight or preterm babies. The fact that there was a crude effect of asthma on perinatal mortality, that the effect vanished after adjusting for birth weight and gestational age at birth, that there is a higher prevalence of low birthweight and preterm babies among women with asthma, that birth weight and gestational age at birth are very strong predictors of perinatal mortality and that there was no effect of asthma on normal weight and term babies suggest that asthma mainly increases the risk of perinatal mortality through lowering the weight of the baby and increasing the risk of a preterm delivery.

This study has several strengths. Using the administrative databases of Quebec presents certain advantages since they provided a large sample size of pregnant women with and without asthma, as well as the possibility of adjusting the risk estimates for a wide variety of potential confounders. Moreover, the information recorded in the administrative databases is prospectively collected, independent of the outcome. In addition, the diagnoses recorded in the RAMQ databases for the identification of patients with asthma are physician-based and have been shown to be valid. ${ }^{23}$

However, this study has a few limitations that should be kept in mind when interpreting the results. Some maternal characteristics are not available in the databases, such as cigarette smoking and obesity. Studies have found that maternal smoking is associated with an increased risk of perinatal mortality, ${ }^{32}$ and women with asthma might be more likely to smoke than those without asthma. ${ }^{811}$ Not adjusting for smoking could therefore result in unadjusted confounding. However, it is expected that a large part of the impact of cigarette smoking would be captured by the variables birth weight, gestational age at birth and placental abruption that are included in our model. Indeed, the increased risk of stillbirth and perinatal mortality among smoking mothers is generally explained by fetal growth restriction, very early delivery and placenta abruption. ${ }^{32}$ Maternal smoking is associated with fetal hypoxia due to the reduction of the uteroplacental blood flow, and the increase in vascular resistance may partly explain the association between smoking and reduced fetal growth and also may contribute to the increased risk of placental abruption. ${ }^{34}$

Obesity might act as a confounder in the association between maternal asthma and perinatal mortality since obesity has been found to be more prevalent in women with asthma than in those without asthma, ${ }^{35}$ and obesity has been associated with an increased risk of stillbirth. ${ }^{36}$ Not adjusting for obesity in our study might have overestimated the impact of asthma on perinatal mortality.

In addition, the RAMO databases provide medication information only for welfare recipients and residents who are covered by Quebec's Public Prescription Drug Insurance Plan; residents who are covered by a private drug insurance plan are excluded. This led to a sample that was under-represented by women with a high socioeconomic status. Socioeconomic status has been associated with an increased risk of perinatal mortality. ${ }^{37}$ Thus, generalisation of our results may be limited to women of lower socioeconomic status.

In conclusion, the increased risk of a low birthweight baby and premature delivery among women with asthma may partly explain the association between maternal asthma and the increased risk of perinatal mortality.

Funding: This project was funded by grants from the Fonds de la recherche en santé du Québec (FRSO) and Canadian Institute for Health Research (CIHR). LB and M-FB are co-chair of the Endowment Pharmaceutical Chair AstraZeneca in Respiratory Health. LB is the recipient of a Junior II investigator salary support from the FRSQ. M-CB is the recipient of a doctoral research scholarship of the FRSO and the Conseil du médicament du Québec. CL is the recipient of a New Investigator Salary Award from the CIHR.

Competing interests: None.

\section{REFERENCES}

1. Kwon HL, Belanger K, Bracken MB. Asthma prevalence among pregnant and childbearing-aged women in the United States: estimates from national health surveys. Ann Epidemiol 2003;13:317-24.

2. Bahna SL, Bjerkedal T. The course and outcome of pregnancy in women with bronchial asthma. Acta Allergol 1972;27:397-406.

3. Stenius-Aarniala B, Piirila P, Teramo K. Asthma and pregnancy: a prospective study of 198 pregnancies. Thorax 1988;43:12-8.

4. Stenius-Aarniala B, Riikonen S, Teramo K. Slow-release theophylline in pregnant asthmatics. Chest 1995;107:642-7; published erratum appears in Chest 1996; 109:1668

5. Lao TT, Huengsburg M. Labour and delivery in mothers with asthma. Eur J Obstet Gynecol Reprod Biol 1990;35:183-90.

6. Mabie WC, Barton JR, Wasserstrum N, et al. Clinical observations on asthma in pregnancy. J Matern Fetal Med 1992;1:45-50. 
7. Jana N, Vasishta K, Saha SC, et al. Effect of bronchial asthma on the course of pregnancy, labour and perinatal outcome. J Obstet Gynaecol 1995;21:227-32.

8. Schatz M, Zeiger RS, Hoffman CP, et al. Perinatal outcomes in the pregnancies of asthmatic women: a prospective controlled analysis. Am J Respir Crit Care Med 1995;151:1170-4.

9. Dombrowski M, Schatz M, Wise R, et al. Asthma during pregnancy. Obstet Gynecol 2004;103:5-12.

10. Sheiner E, Mazor M, Levy A, et al. Pregnancy outcome of asthmatic patients: a population-based study. J Matern Fetal Neonat Med 2005;18:237-40.

11. Schatz M, Zeiger RS, Harden KM, et al. The safety of inhaled beta-agonist bronchodilators during pregnancy. J Allergy Clin Immunol 1988;82:686-95.

12. Sobande AA, Archibong El, Akinola SE. Pregnancy outcome in asthmatic patients from high altitudes. Int J Gynaecol Obstet 2002;77:117-21.

13. Gordon M, Niswander KR, Berendes $\mathrm{H}$, et al. Fetal morbidity following potentially anoxigenic obstetric conditions. VII. Bronchial asthma. Am J Obstet Gynecol 1970;106:421-9.

14. Greenberger PA, Patterson R. Beclomethasone diproprionate for severe asthma during pregnancy. Ann Intern Med 1983;98:478-80.

15. Fitzsimons R, Greenberger PA, Patterson R. Outcome of pregnancy in women requiring corticosteroids for severe asthma. J Allergy Clin Immunol 1986;78:349-53.

16. Greenberger PA, Patterson R. The outcome of pregnancy complicated by severe asthma. Allergy Proc 1988;9:539-43.

17. Kallen B, Rydhstroem H, Aberg A. Asthma during pregnancy-a population based study. Eur J Epidemiol 2000;16:167-71.

18. Wen SW, Demissie K, Liu S. Adverse outcomes in pregnancies of asthmatic women: results from a Canadian population. Ann Epidemiol 2001;11:7-12.

19. Norjavaara E, de Verdier MG. Normal pregnancy outcomes in a population-based study including 2968 pregnant women exposed to budesonide. J Allergy Clin Immunol 2003;111:736-42.

20. Kallen B, Otterblad OP. Use of anti-asthmatic drugs during pregnancy. 2. Infant characteristics excluding congenital malformations. Eur J Clin Pharmacol 2007;63:375-81.

21. Tata L, Lewis $S$, McKeever $T$, et al. A comprehensive analysis of adverse obstetric and pediatric complications in women with asthma. Am J Respir Crit Care Med 2007; 175:991-7.

22. Blais $\mathbf{L}$, Beauchesne MF, Rey $\mathrm{E}$, et al. Use of inhaled corticosteroids during the first trimester of pregnancy and the risk of congenital malformations among women with asthma. Thorax 2007;62:320-8.
23. Blais L, Lemière C, Menzies D, et al. Validity of asthma diagnoses recorded in the Medical Services database of Quebec. Pharmacoepidemiol Drug Saf 2005;15:245-52.

24. Martel MJ, Rey É, Beauchesne MF, et al. Use of inhaled corticosteroids during pregnancy and risk of pregnancy induced hypertension: nested case-control study. BMJ 2005;330:230-3.

25. Vilain A, Otis $S$, Forget $A$, et al. Agreement between administrative databases and medical charts for pregnancy-related variables among asthmatic women. Pharmacoepidemiol Drug Saf 2008;17:345-53.

26. Liu S, Wen SW, Demissie K, et al. Maternal asthma and pregnancy outcomes: a retrospective cohort study. Am J Obstet Gynecol 2001;184:90-6.

27. Wilcox AJ, Skjaerven R. Birth weight and perinatal mortality: the effect of gestational age. Am J Public Health 1992;82:378-82.

28. Bernstein IM, Horbar JD, Badger GJ, et al. Morbidity and mortality among very-lowbirth-weight neonates with intrauterine growth restriction. The Vermont Oxford Network. Am J Obstet Gynecol 2000;182(1 Pt 1):198-206.

29. Bracken MB, Triche EW, Belanger K, et al. Asthma symptoms, severity, and drug therapy: a prospective study of effects on 2205 pregnancies. Obstet Gynecol 2003; 102:739-52.

30. Morrison JC. Preterm birth: a puzzle worth solving. Obstet Gynecol 1990;76(1 Suppl):5-12S.

31. Getahun D, Ananth CV, Peltier MR, et al. Acute and chronic respiratory diseases in pregnancy: associations with placental abruption. Am J Obstet Gynecol 2006;195:1180-4.

32. Meyer M, Jonas B, Tonascia J. Perinatal events associated with maternal smoking during pregnancy. Am J Epidemiol 1976;103:464-76.

33. Raymond EG, Cnattingius S, Kiely JL. Effects of maternal age, parity, and smoking on the risk of stillbirth. Br J Obstet Gynaecol 1994;101:301-6.

34. Kramer MS, Usher RH, Pollack R, et al. Etiologic determinants of abruptio placentae. Obstet Gynecol 1997;89:221-6.

35. Hendler I, Schatz M, Momirova V, et al. Association of obesity with pulmonary and nonpulmonary complications of pregnancy in asthmatic women. Obstet Gynecol 2006;108:77-82.

36. Nohr EA, Bech BH, Davies MJ, et al. Prepregnancy obesity and fetal death: a study within the Danish national birth cohort. Obstet Gynecol 2005;106:250-9.

37. Devlieger H, Martens G, Bekaert A. Social inequalities in perinatal and infant mortality in the northern region of Belgium (the Flanders). Eur $\mathrm{J}$ Public Health 2005;15:15-9.

\section{Lung alert}

\section{Survival prediction in early squamous cell lung cancer}

Current staging methods of squamous cell carcinoma (SCC) do not provide information regarding long-term prognosis. Gene expression profiling may be useful in this area.

In this study, lung SCC tumours resected from 66 patients between 2000 and 2004 in a Polish centre were identified for gene transcriptional analysis. A second cohort (validation group) of 26 patients was also studied. Tumour samples resected at surgery were used to study gene expression. A risk score model was designed to classify patients into good and poor survival groups. The degree of expression of 10 genes (CSF1, EGFR, CA IX, PH4, KIAA0974, ANLN, VEGFC, NTRK1, FN1 and INR1) was found to correlate with survival. In a subsequent multivariate analysis, three-gene signature (CSF1, EGFR, CA IX) and tumour size were found to have further independent useful predictive value for survival.

This study does have limitations; the range of the confidence interval is large due to the small sample size. Although the authors conclude the three genes are strongly associated with prognosis, this non-interventional study does not confirm the survival benefit of adjuvant chemotherapy. Also, the follow-up period is only 3 years and the sample size in the validation group is too small to give any convincing long-term conclusions.

- Skrzypski M, Jassem E, Taron M, et al. Three-gene expression signature predicts survival in early-stage squamous cell carcinoma of the lung. Clin Cancer Res 2008;14:4794-9.

\section{K Wu}

Correspondence to: Dr K Wu, Specialist Registrar, St James' University Hospital, Leeds, UK; kenwu@doctors.org.uk 
Mean pre- and post-challenge values were analysed with a paired $t$ test. Analyses were performed using SPSS version 15.0 (Chicago, Illinois, USA).

The mean age of the patients was 38 . 5 years. Thirty-eight patients had a methacholine $\mathrm{PC}_{20}<8 \mathrm{mg} / \mathrm{ml}$. The mean fall in $\mathrm{FEV}_{1}$ was $21 \%$. Geometric mean pre-challenge $\mathrm{FE}_{\mathrm{NO}}$ was $20.4 \mathrm{ppb}$ compared with $16.9 \mathrm{ppb}$ post-challenge, a difference of $17 \%$ (95\% CI $13 \%$ to $21 \%, p<0.001$; fig 1$)$. Geometric mean $\mathrm{CA}_{\mathrm{NO}}$ was $2.9 \mathrm{ppb}$ pre-challenge and $1.9 \mathrm{ppb}$ post-challenge, a difference of $31 \%$ (95\% CI $17 \%$ to $43 \%, \mathrm{p}<0.001)$. Differences in $\mathrm{NO}$ at flow rates of 50,100 and $200 \mathrm{ml}$ were $15 \%$ (95\% CI $10 \%$ to $19 \%), 11 \%$ (95\% CI $6 \%$ to $16 \%$ ) and $17 \%$ (95\% CI $11 \%$ to $22 \%$ ), respectively $(p<0.001)$. Baseline values for $\mathrm{FE}_{\mathrm{NO}}$ and $\mathrm{CA}_{\mathrm{NO}}$ showed no correlation with methacholine $\mathrm{PC}_{20}$, baseline $\mathrm{FEV}_{1}$ or final percentage fall in $\mathrm{FEV}_{1}$. The percentage change in $\mathrm{CA}_{\mathrm{NO}}$ following challenge showed a positive correlation with the baseline value $(\mathrm{r}=0.59, \mathrm{p}<0.001)$.

To our knowledge, this is the first study to report the effects of methacholine challenge on $\mathrm{CA}_{\mathrm{NO}}$. We have shown that methacholine challenge significantly reduces $\mathrm{CA}_{\mathrm{NO}}$, and this effect is relatively more marked than for $\mathrm{FE}_{\mathrm{NO}}$. The effect on $\mathrm{FE}_{\mathrm{NO}}$ is known, and is thought to be due to washout of nitric oxide from the airways. There was a proportionally greater suppression of $\mathrm{FE}_{\mathrm{NO}}$ at $200 \mathrm{ml}(17 \%)$ than at $50 \mathrm{ml}(15 \%)$ and $100 \mathrm{ml}(11 \%)$. This has a more significant effect on the slope of the regression line and hence the $\mathrm{CA}_{\mathrm{NO}}$ is relatively more suppressed than $\mathrm{FE}_{\mathrm{NO}}$. This is an important consideration for planning and interpreting study visits in clinical trials.

P A Williamson, K Clearie, S Vaidyanathan, B Lipworth Asthma and Allergy Research Group, University of Dundee, Ninewells Hospital and Medical School, Dundee, UK

Correspondence to: Dr P A Williamson, Asthma and Allergy Research Group, University of Dundee, Ninewells Hospital and Medical School, Dundee DD1 9SY, UK; p.a.williamson@dundee.ac.uk

\section{Competing interests: None.}

Accepted 4 February 2009

Thorax 2009;64:549-550. doi:10.1136/thx.2009.113548

\section{REFERENCES}

1. ATS/ERS. ATS/ERS recommendations for standardized procedures for the online and offline measurement of exhaled lower respiratory nitric oxide and nasal nitric oxide, 2005. Am J Respir Crit Care Med 2005;171:912-30.

2. Silkoff PE, Erzurum SC, Lundberg JO, et al. ATS workshop proceedings: exhaled nitric oxide and nitric oxide oxidative metabolism in exhaled breath condensate. Proc Am Thorac Soc 2006;3:131-45.
3. Tsoukias NM, Shin HW, Wilson AF, et al. A singlebreath technique with variable flow rate to characterize nitric oxide exchange dynamics in the lungs. J Appl Physiol 2001;91:477-87.

\section{CORRECTION}

doi:10.1136/thx.2008.102970corr1

M-C Breton, M-F Beauchesne, C Lemière, et al. Risk of perinatal mortality associated with asthma during pregnancy. Thorax 2009;64:101-6. The values for parity 1 and parity $\geqslant 2$ in table 2 were transposed. The correct table is printed below.
Table 2 Crude and adjusted odds ratios (ORs) of perinatal mortality in women with and without asthma for the complete and final model $(n=41$ 142)

\begin{tabular}{|c|c|c|c|}
\hline & Crude OR $(95 \% \mathrm{CI})$ & $\begin{array}{l}\text { Adjusted OR for all } \\
\text { covariates }(95 \% \mathrm{CI})\end{array}$ & $\begin{array}{l}\text { Adjusted OR for } \\
\text { confounders only } \\
(95 \% \mathrm{CI})\end{array}$ \\
\hline Asthma yes/no & 1.35 (1.08 to 1.67$)$ & $0.95(0.74$ to 1.22$)$ & $0.93(0.75$ to 1.17$)$ \\
\hline \multicolumn{4}{|l|}{ Age } \\
\hline$<18$ & $1.19(0.73$ to 1.91$)$ & 0.91 (0.49 to 1.69$)$ & $\dagger$ \\
\hline $18-34$ & Reference (-) & Reference (-) & \\
\hline$\geqslant 35$ & 1.59 (1.16 to 2.18$)$ & $1.40(0.97$ to 2.01$)$ & \\
\hline Social assistance yes/no & $1.32(1.05$ to 1.67$)$ & $0.80(0.60$ to 1.06$)$ & $\dagger$ \\
\hline \multicolumn{4}{|l|}{ Level of education } \\
\hline$\leqslant 11$ & 1.25 (0.98 to 1.59$)$ & $0.95(0.72$ to 1.26$)$ & $\dagger$ \\
\hline$\geqslant 12$ & Reference (-) & Reference (-) & - \\
\hline Missing & 4.49 (3.39 to 5.95$)$ & $2.44(1.73$ to 3.45$)$ & \\
\hline \multicolumn{4}{|l|}{ Parity } \\
\hline 1 & Reference (-) & Reference & $\dagger$ \\
\hline$\geqslant 2$ & $1.13(0.89$ to 1.43$)$ & $1.12(0.86$ to 1.47$)$ & \\
\hline PIH yes/no & $1.24(0.82$ to 1.89$)$ & $0.53(0.32$ to 0.87$)$ & $\dagger$ \\
\hline Diabetes mellitus yes/no & $1.97(1.07$ to 3.60$)$ & $1.58(0.79$ to 3.18$)$ & $\dagger$ \\
\hline Gestational diabetes yes/no & $0.80(0.51$ to 1.26$)$ & $0.72(0.43$ to 1.21$)$ & $\dagger$ \\
\hline Placental abruption yes/no & 7.33 (5.59 to 9.62$)$ & $1.75(1.28$ to 2.40$)$ & $\dagger$ \\
\hline Infection of amniotic cavity yes/no & $3.74(2.80$ to 4.99$)$ & $1.92(1.37$ to 2.68$)$ & $\dagger$ \\
\hline Cord around neck yes/no & $0.74(0.55$ to 1.01$)$ & $0.86(0.61$ to 1.21$)$ & $\dagger$ \\
\hline Birth weight $\leqslant 2500 />2500 \mathrm{~g}$ & 34.75 (27.58 to 43.79$)$ & $10.55(7.40$ to 15.15$)$ & $9.11(6.61$ to 15.55$)$ \\
\hline $\begin{array}{l}\text { Gestational age at birth }<37 / \geqslant 37 \\
\text { weeks }\end{array}$ & 30.62 (24.27 to 38.63$)$ & 6.24 (4.37 to 8.90$)$ & 7.07 (5.12 to 9.77$)$ \\
\hline
\end{tabular}

†Not a confounder variable.

$\mathrm{PIH}$, pregnancy-induced hypertension. 